\title{
A PERCEPÇÃO AMBIENTAL DE ALUNOS DE UM COLÉGIO PÚBLICO DO MUNICÍPIO DE MANDIRITUBA/PR QUANTO AOS RESÍDUOS SÓLIDOS
}

The environmental awareness of students of a public school in the municipality of Mandirituba / PR regarding solid waste

La conciencia ambiental de los estudiantes de una escuela pública en la ciudad de Mandirituba / PR en materia de residuos sólidos

Everton Mario de Oliveira

Geógrafo, Mestre em Ciência e Tecnologia Ambiental, Universidade Tecnológica Federal do Paraná (UTFPR), Programa de Pós Graduação em Ciência e Tecnologia Ambiental/ PPGCTA/ CEP - 81280-340 - Curitiba - Paraná - Brasil. Email: everton.utp@hotmail.com

Fátima de Jesus Bassetti

Engenheira Química, Doutora em Engenharia Química pela Universidade Estadual de Campinas. Professora da Universidade Tecnológica Federal do Paraná (UTFPR), Programa de Pós Graduação em Ciência e Tecnologia Ambiental/ PPGCTA/ CEP - 81280-340 - Curitiba - Paraná - Brasil. Email: bassetti@utfpr.edu.br 


\section{RESUMO}

Os resíduos sólidos constituem um dos grandes problemas enfrentados pela sociedade. Uma das formas de minimizar a geração de resíduos é sensibilizar e conscientizar a população por meio da aplicação de projetos de educação ambiental. Porém, antes de iniciar um projeto de educação ambiental é necessário realizar um diagnóstico da percepção ambiental do público alvo, para estabelecer os objetivos e os métodos a serem desenvolvidos. A presente pesquisa teve como objetivo avaliar a percepção ambiental de alunos de um colégio público de Mandirituba/PR, referente aos resíduos sólidos. Para isto, foi elaborado e aplicado aos alunos um questionário contendo questões abertas e fechadas sobre resíduos sólidos. Após a análise dos dados obtidos com as respostas dos alunos, notou-se que, de forma geral, os estudantes apresentaram uma percepção ambiental incipiente, pois não souberam responder a algumas questões e, não se verificou uma conscientização em todos os indivíduos da comunidade em relação à separação dos resíduos, sendo que muitos não realizam a separação e destinação adequada dos resíduos sólidos. Entretanto, os alunos demonstraram compreender a importância de realizar a seleção dos resíduos sólidos e também conhecem as consequências que o gerenciamento inadequado dos resíduos causa ao meio ambiente. Também percebeu-se a importância da escola como veículo de formação de conhecimento, sendo considerada o ambiente mais propício ao desenvolvimento de estratégias de educação ambiental.

PALAVRAS-CHAVE: Educação ambiental. Percepção ambiental. Resíduos sólidos.

\section{ABSTRACT}

Solid waste is one of the major problems faced by society. One way to minimize the generation of waste is to sensitize and educate the population through the application of environmental education projects. However, before starting a project of environmental education is necessary to make a diagnosis of environmental perception of the audience, to establish the objectives and the methods to be developed. This research aimed to evaluate the environmental perception of students of a public school in Mandirituba / PR, related to solid waste. To this, was elaborated and applied students a questionnaire containing open and closed questions on solid waste. After analyzing the data obtained from the students' responses, it was noted that, in general, students showed an incipient environmental perception, it could not answer some questions, and there was an awareness in all individuals in the community regarding separation of waste, and many do not realize the separation and proper disposal of solid waste. However, students demonstrated understanding the importance of making the selection of solid waste and also know the consequences that inadequate management of waste causes to the environment. Also realized the importance of the school as a vehicle for knowledge building and is considered the most suitable for the development of strategies for environmental education environment.

KEYWORDS: Environmental education. Environmental perception. Solid waste.

\section{RESUMEN}

Los residuos sólidos es uno de los principales problemas que enfrenta la sociedad. Una forma de minimizar la generación de residuos es sensibilizar y educar a la población a través de la aplicación de proyectos de educación ambiental. Pero antes de empezar un proyecto de educación ambiental es necesario llevar a cabo un diagnóstico de la percepción ambiental del público objetivo, establecer los objetivos y los métodos que deberán elaborarse. Esta investigación tuvo como objetivo evaluar la conciencia ambiental de los estudiantes de una escuela pública de Mandirituba / PR, relacionado con los residuos sólidos. Para esto, se desarrolló y aplicó a los estudiantes un cuestionario con preguntas abiertas y cerradas sobre residuos sólidos. Después de analizar los datos obtenidos a partir de las respuestas de los estudiantes, se observó que, en general, los estudiantes mostraron una percepción ambiental incipiente, porque no hay respuesta a algunas preguntas $y$, existía una conciencia en todos los individuos de la comunidad relación con la separación de los residuos, y muchos no se dan cuenta de la separación y la disposición adecuada de los residuos sólidos. Sin embargo, los estudiantes demostraron comprender la importancia de hacer la selección de los residuos sólidos y también saben las consecuencias que causa inadecuada gestión de residuos para el medio ambiente. También se dio cuenta de la importancia de la escuela como un vehículo para la formación del conocimiento, siendo considerado el más propicio para el desarrollo de estrategias de educación medio ambiental.

PALABRAS CLAVE: Educación ambiental. Conciencia ambiental. Residuos sólidos. 


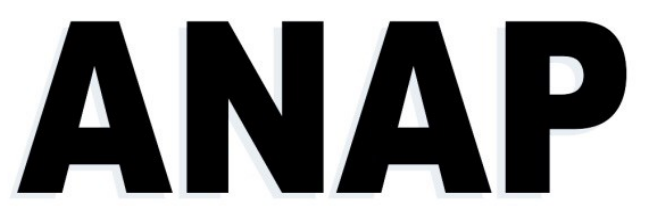

Brasil

ISSN 1984-3240

v. 9, n. 14

\section{INTRODUÇÃO}

Um dos grandes problemas ambientais das cidades atualmente é a geração excessiva de resíduos sólidos (AZEVEDO, 2004), sobretudo, porque geralmente esses resíduos são destinados de maneira inadequada (MUCELIN; BELLINI, 2008). A cada dia são coletadas entre 180 e 250 mil toneladas de resíduos sólidos urbanos no Brasil (GOUVEIA, 2012), sendo que a gestão mais adequada do ponto de vista ambiental desses resíduos deve começar com a conscientização da população, visando primeiramente a não geração, passando também pela minimização da geração, reutilização, reciclagem e tratamento (COELHO et al., 2011). Sendo assim, a questão dos resíduos sólidos merece ser tratada com mais atenção pelos governantes dos municípios brasileiros, dentre eles o município de Mandirituba que é um dos 399 municípios paranaenses, localizado na Região Metropolitana de Curitiba. O município possui uma população de 22220 habitantes (IBGE, 2010) e uma área territorial de aproximadamente $381 \mathrm{~km}^{2}$ (IPARDES, 2012). A Figura 1 representa a localização do município de Mandirituba.

Figura 1: Localização do município de Mandirituba.

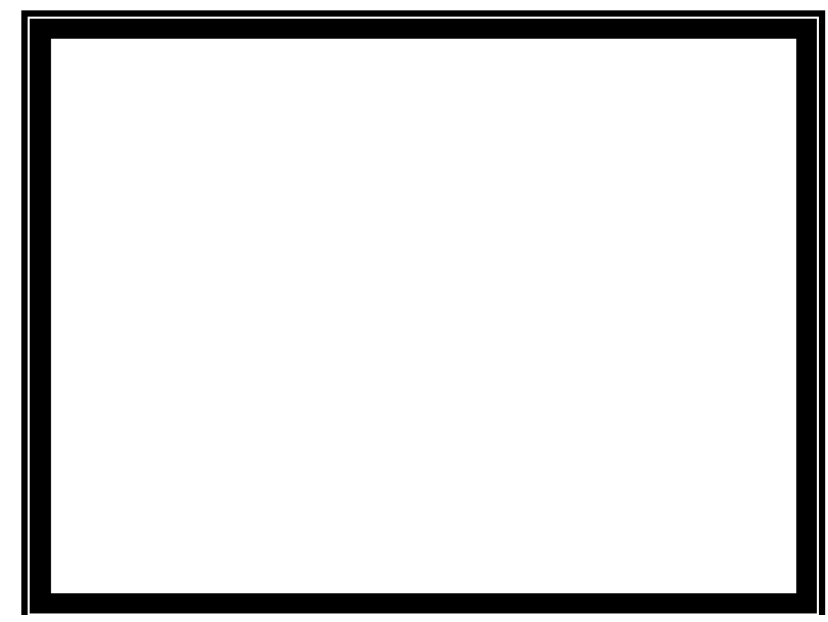

Fonte: Adaptado de Prefeitura Municipal de São José dos Pinhais (2014).

Dos 6718 domicílios existentes em Mandirituba, 5134 têm seus resíduos sólidos coletados. Dos domicílios que possuem coleta seletiva, o serviço de limpeza pública do município coleta resíduos de 4795 e, dos outros 339 domicílios, os resíduos são coletados pelo serviço de limpeza privada. Restam ainda 1584 domicílios que permanecem sem a coleta de resíduos sólidos (IBGE, 2010).

Segundo entrevista realizada na Secretaria Municipal de Meio Ambiente, $70 \%$ dos bairros e comunidades do município são atendidos pela coleta seletiva, que é realizada com a utilização de um caminhão específico para coleta de resíduos recicláveis no método denominado "porta a porta", no qual o veículo percorre as ruas e estradas principais de cada comunidade coletando os resíduos das casas que ficam às margens dessas estradas. Para os moradores de ruas secundárias, onde o caminhão não passa, existem pontos estratégicos de coleta às margens da rua principal, que são compartilhados por esses moradores, como pode ser observado na Figura 2. 


\section{ANAP

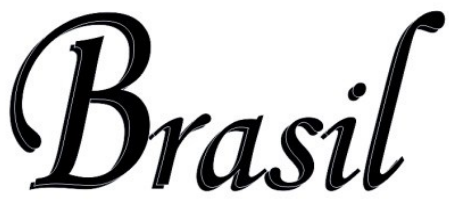 \\ ISSN 1984-3240 V. 9, n. 14}

Figura 2: Fotografias de pontos de coleta de resíduos recicláveis compartilhados por moradores que não são atendidos pelo método "porta a porta", localizados nas proximidades da comunidade de Areia Branca dos Assis.

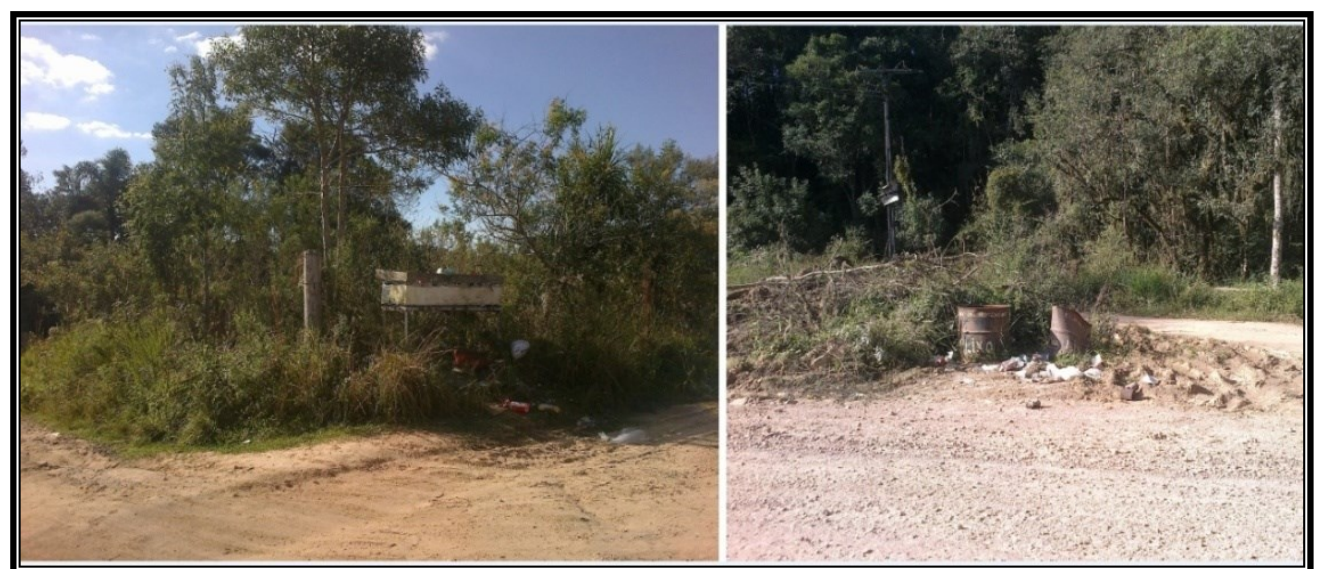

Fonte: Autoria própria (2013).

Os resíduos sólidos recicláveis coletados em Mandirituba são encaminhados para um centro de valorização de resíduos, localizado no próprio município, onde são separados por catadores cadastrados pela prefeitura e, posteriormente são vendidos no município de Curitiba para indústrias recicladoras.

Ainda, segundo entrevista realizada na Secretaria Municipal de Meio Ambiente, $100 \%$ da área urbana (formada pelas localidades Centro, Areia Branca dos Assis, Lagoinha, Vila Brasília e Queimados) possui coleta de resíduos sólidos orgânicos. Essa coleta é realizada de maneira "convencional", onde a maioria dos moradores não separa os resíduos recicláveis dos orgânicos.

$\mathrm{Na}$ área rural a coleta dos resíduos orgânicos é realizada em pontos estratégicos, que são locais construídos pela prefeitura, onde os moradores residentes no entorno depositam os resíduos orgânicos para que uma vez por semana, a prefeitura possa fazer a coleta desses resíduos. Existem cerca de 15 pontos estratégicos de coleta de resíduos orgânicos distribuídos pela área rural de Mandirituba, semelhantes ao ilustrado na Figura 3. Os resíduos sólidos orgânicos coletados em Mandirituba são encaminhados ao aterro sanitário localizado no município de Fazenda Rio Grande. 


\section{ANAP}

utilizados pela população e/ou estão com prazo de validade vencido, são recolhidos no hospital municipal de Mandirituba e postos de saúde do município e, posteriormente, são coletados junto com os resíduos do serviço de saúde. Embalagens de agrotóxicos são coletadas por uma empresa particular apenas duas vezes por ano. Óleos lubrificantes, graxas, entre outros, são coletados por empresa particular apenas em postos de combustíveis.

Ainda, segundo a Secretaria Municipal de Meio Ambiente, os outros resíduos perigosos como lâmpadas, pilhas e baterias não são contemplados por nenhum sistema de coleta diferenciada, ficando sob responsabilidade do município de Mandirituba.

Uma das formas de melhorar a gestão de resíduos sólidos é a utilização de ações de educação ambiental que promovam a sensibilização e a conscientização das pessoas. Segundo Marcomin et al. (2013, p. 102) os "problemas ambientais de ordem local favorecem a sensibilização ambiental, pois, se constituem em espaços conhecidos dos indivíduos, afetando-os de modo mais direto e intenso".

Para iniciar um projeto de educação ambiental, é necessário primeiramente conhecer a realidade do público alvo (MONTEIRO et al., 2012), através da realização de um diagnóstico da percepção ambiental (SANTOS et al., 2013).

A percepção ambiental pode ser definida como sendo a tomada de consciência dos problemas ligados ao meio ambiente, ato de perceber o ambiente onde o próprio ser humano está inserido, aprendendo a preservar o mesmo (VILLAR et al., 2008). Dessa forma, a percepção ambiental é individual, construída e interpretada por cada indivíduo (MACEDO et al., 2010).

A percepção ambiental é utilizada como forma de averiguar os valores atribuídos a um lugar, auxiliar o planejamento ambiental e favorecer o desenvolvimento de sociedades sustentáveis (SILVA et al., 2011), devendo ser utilizada como um instrumento para identificar pontos positivos e negativos na relação entre homem e natureza (MARQUES; FILHO; MAGALHÃES, 2011). Além disso, é um pré-requisito para se atingir diferentes níveis de conscientização ambiental (MACEDO et al., 2010). Conhecer a percepção ambiental do indivíduo é de grande importância para poder identificar e descrever alguns problemas ambientais, além de registrar a opinião coletiva, seus anseios, observações e expectativas (MENEZES; BERTOSSI, 2011).

A busca das identidades e percepções dos sujeitos envolvidos no projeto de educação ambiental deve ocorrer com base em instrumentos de coleta de dados, como conversas, entrevistas ou questionários (SPAZZIANI; SILVA, 2009), como forma de avaliar possíveis diferenças, olhares e dimensões antes e após as atividades de sensibilização (CAMPOS et al., 2012).

As escolas são um dos locais mais apropriados para o desenvolvimento da educação ambiental, pois é dentro das escolas que os futuros cidadãos são envolvidos em discussões e reflexões referentes às questões ambientais (CASSERES, 2011). De acordo com Souza (2013, p. $120)$, os "comportamentos ambientalmente corretos devem ser aprendidos na prática, e a escola, pode contribuir significativamente para esse processo através da formação de sujeitos críticos e reflexivos capazes de atuar na complexa realidade socioambiental".

Diante do exposto, esse trabalho teve como objetivo realizar um diagnóstico da percepção ambiental de alunos de um colégio estadual localizado na comunidade de Areia Branca dos Assis, município de Mandirituba/PR, quanto ao gerenciamento doméstico dos resíduos sólidos. 


\section{ANAP

\section{MATERIAL E MÉTODOS}

O estudo foi desenvolvido em uma escola da comunidade de Areia Branca dos Assis, distrito urbano do município de Mandirituba localizado a aproximadamente $11 \mathrm{~km}$ da sede municipal, com quem mantém ligação viária através da Rodovia Federal BR 116. Trata-se de uma pequena área urbana com cerca de 3500 habitantes.

A escola escolhida para a realização do projeto atende cerca de 950 alunos de ensino fundamental e médio, que estudam nos três turnos (manhã, tarde e noite). Esses alunos pertencem em sua maioria à faixa etária entre 10 e 17 anos. Aproximadamente $56 \%$ dos alunos residem na comunidade de Areia Branca dos Assis e os $44 \%$ restantes moram nas comunidades rurais vizinhas.

Para a realização do diagnóstico da percepção ambiental dos alunos, foi utilizado um questionário como instrumento de coleta de dados. O desenvolvimento do questionário está ligado à formulação exata do problema a ser pesquisado e do objetivo da pesquisa (CHAGAS, 2000). Assim, foram desenvolvidos questionários do tipo misto, tendo como tema principal resíduo sólido.

A linguagem e o tom das questões que constituem um questionário são de elevada importância (AMARO; PÓVOA; MACEDO, 2004/2005). Como a faixa etária da maioria dos alunos que estuda no colégio em Areia Branca dos Assis varia entre 10 e 17 anos, o questionário apresenta linguagem simplificada para possibilitar a compreensão das questões pelas diferentes faixas de idade.

Após a elaboração das perguntas, Moysés e Moori (2007) recomendam que se faça uma validação do questionário, ou seja, o questionário precisa ser avaliado antes da sua utilização definitiva. A validação foi realizada distribuindo-se o questionário a $5 \%$ dos alunos (cerca de 50 alunos), que foram escolhidos de forma aleatória em 10 turmas do Ensino Fundamental e Médio. Para a escolha dos alunos em cada sala, foi perguntado quem se dispunha a responder o questionário. Dessa forma, os alunos tiveram liberdade para responder ou não ao questionário, de maneira voluntária.

Com a análise do questionário, notou-se que faltaram questões que contemplassem a gestão dos resíduos sólidos, que foram adicionadas posteriormente, tendo em vista aproveitar o máximo de informações que os alunos poderiam oferecer. Também foi necessário transformar algumas questões fechadas em abertas, visando ao colaborador expressar sua opinião e também um melhor aproveitamento do espaço entre as questões. O questionário, após ser reestruturado, pode ser observado no Quadro 1. 


\section{ANAP

\section{Quadro 1: Questionário aplicado aos alunos.}

1 Quantos anos você completou ou completará nesse ano?

2 Qual série/ano você estuda?

3 Qual turno você estuda?

4 Em qual bairro/localidade você mora?

5 Qual o nível de escolaridade de seu pai?

( ) Não estudou

( ) Ensino Fundamental incompleto

( ) Ensino Fundamental completo

( ) Ensino Médio incompleto

( ) Ensino Médio completo

( ) Ensino Superior incompleto

( ) Ensino Superior completo

( ) Pós-Graduação

6 Qual o nível de escolaridade de sua mãe?

( ) Não estudou

( ) Ensino Fundamental incompleto

( ) Ensino Fundamental completo

( ) Ensino Médio incompleto

( ) Ensino Médio completo

( ) Ensino Superior incompleto

( ) Ensino Superior completo

( ) Pós-Graduação

7 Quantas pessoas moram em sua casa?

8 Qual é a renda mensal de sua família?

( ) Até 2 salários mínimos (até $R \$ 1244,00$ )

( ) Entre 2 e 3 salários mínimos (entre $R \$ 1244,00$ e $\mathrm{R} \$ 1866,00)$

( ) Entre 3 e 4 salários mínimos (entre $R \$ 1866,00$ e $\mathrm{R} \$ 2488,00)$

( ) Mais de 4 salários mínimos (mais de $R \$ 2488,00$ )

9 Você sabe o que é "lixo"?

( ) Não

( ) Sim. Explique:

100 "lixo" pode causar problemas?

( ) Não

( ) Sim. Quais?
11 Se sua resposta foi sim na pergunta anterior, onde você aprendeu sobre os problemas causados pelo "lixo"?

( ) Escola ( ) Jornal

( ) Televisão ( ) Revistas

( ) Internet ( ) Outros

12 Você acha importante separar o "lixo"?

( ) Sim

( ) Não

( ) Não sei

13 Existe coleta de "lixo" em sua casa?

( ) Sim

( ) Não

14 Se existe, quem realiza a coleta de "lixo"em sua casa?

( ) Caminhão da prefeitura

( ) Catadores

15 Que tipo de "lixo" é coletado?

( ) Recicláveis

( ) Orgânicos

( ) Os dois tipos

16 Sua família separa o "lixo" em sua casa?

( ) Sempre

( ) Às vezes

( ) Não separa

17 Qual tipo de "lixo" é produzido em maior quantidade em sua casa?

( ) Plástico

( ) Papel

( ) Vidro

( ) Metais

( ) Resto de comida

( ) Não sei

18 Você sabe a diferença entre "lixo" reciclável e "lixo" orgânico?

( ) Não

( ) Sim. Explique:

19 Para onde vai o "lixo" depois que sai da sua casa?

Fonte: Autoria própria (2013).

Como o total de alunos que estudam no colégio é elevado (cerca de 950), optou-se por aplicar os questionários a 510 alunos e, desse total, foi escolhida aleatoriamente uma amostra de 288 
questionários para a realização das análises, o que corresponde a $30,3 \%$ da totalidade de alunos que frequentam o colégio.

Os questionários foram aplicados em todas as turmas. Primeiramente foi solicitada a permissão ao professor que ministrava aula na turma, explicando aos alunos que se tratava de uma pesquisa referente a resíduos sólidos e, perguntado quais alunos gostariam de ser voluntários para responder o questionário.

Foram separados, previamente, 17 questionários para cada turma. Em algumas turmas, principalmente do período noturno, a quantidade de alunos era inferior ao número de questionários oferecidos, assim, sobravam alguns questionários. Porém, em turmas dos períodos manhã e tarde, com número maior de alunos, frequentemente mais de 17 alunos por turma gostariam de responder ao questionário. Dessa maneira, os questionários que sobraram em um período foram respondidos por alunos de outros períodos. Em algumas turmas faltaram questionários, pois os alunos se mostraram muito interessados em participar.

Para as análises foram utilizadas apenas algumas perguntas do questionário, as demais questões serviram para caracterização da escola e do público alvo. Os questionários foram agrupados por série escolar para facilitar a análise. Os resultados foram convertidos em planilhas "Microsoft Excel". Para melhor visualização dos dados, fez-se uso de gráficos para representar algumas questões que estão organizadas em subitens.

\section{RESULTADOS E DISCUSSÃO}

A partir das questões formuladas (questões abertas e fechadas / Quadro 1) realizou-se a compilação das respostas, sendo as mesmas expostas na sequência.

\section{Percepção dos alunos sobre o tema "lixo"}

Quando os alunos foram questionados sobre a compreensão do que é "lixo", 78,1\% ( $N=288$ ) afirmaram saber do que se trata. Porém, foi solicitado aos alunos que afirmaram saber o que são os resíduos sólidos, que explicassem sua resposta, elaborando um pequeno parágrafo descrevendo sua concepção quanto ao tema "lixo". Com essa descrição que os alunos elaboraram, foi possível identificar e quantificar os alunos que realmente são capazes de compreender e explicar o que são resíduos sólidos. Percebeu-se que entre os $78,1 \%$ dos alunos que afirmaram ter conhecimento sobre o tema "lixo", apenas $48,7 \%$ descreveram explicações mais exatas. Cerca de $51,3 \%$ dos alunos que relataram ter conhecimento sobre resíduos sólidos, não souberam explicar suas respostas, sendo considerados como alunos que não sabem o que é "lixo". Dessa maneira, somando-se os alunos que relataram saber o que é "lixo", mas não souberam explicar suas respostas, com os alunos que previamente responderam não saber o que é "lixo", nota-se que $62 \%$ dos alunos não sabem o que é "lixo".

Estes dados comprovam que existem falhas no processo ensino-aprendizagem referente aos resíduos sólidos, pois o número maior que $60 \%$, correspondente aos alunos que não souberam explicar sua concepção sobre "lixo", é bastante elevado. Mesmo com o trabalho realizado pela prefeitura, incentivando o acesso à informação por meio de cartilhas (Figura 4), os dados sugerem que grande parte da população não está sendo atingida por essa iniciativa, as pessoas devem estar recebendo a informação, mas o conhecimento não está sendo aprendido. Segundo Correa et al. (2012), a comunicação de conhecimento à população é fundamental para que a questão dos resíduos sólidos seja tratada adequadamente. A população mais 
informada pode tornar-se mais consciente dos problemas ambientais (SILVEIRA; AFONSO; ARRUDA, 2008).

\section{Percepção dos alunos sobre problemas causados pelos resíduos sólidos}

Quando indagados sobre os problemas que podem ser causados pelo descarte inadequado dos resíduos sólidos, $44,5 \%(\mathrm{~N}=288)$ dos alunos apontaram as doenças como sendo o principal problema; 30,5\% dos alunos associaram os resíduos sólidos à poluição; 9,7\% apontaram as enchentes como principal problema; e 15,3\% não associaram os resíduos sólidos a nenhum problema, respondendo que os resíduos sólidos não causam problemas.

Segundo Helal e Felix (2011), em estudo realizado sobre a implantação da coleta seletiva em um condomínio de casas, verificou-se que cerca de $75 \%$ das pessoas entrevistadas apresentaram preocupação com a questão dos resíduos sólidos e com os impactos decorrentes da gestão inadequada. Conforme demonstrado nos dados referentes a esta questão, os alunos também possuem a percepção dos problemas. Porém, os 15,3\% dos alunos que responderam que os resíduos sólidos não causam nenhum problema, representam uma importante parcela dos estudantes que necessita, primeiramente, obtenção de conhecimento referente a resíduos sólidos, e de posterior processo de sensibilização. Logo, uma das maneiras de contribuir para a minimização de tais problemas é sensibilizar os indivíduos, visando leválos a mudanças de suas atitudes perante os resíduos sólidos. Programas de educação ambiental que expõem os alunos aos problemas ambientais são de fundamental importância (MAYER; FRANTZ, 2013), pois melhoram a aprendizagem dos estudantes (BLANCHET-COHEN; REILLY, 2013).

\section{Local onde obteve conhecimento dos problemas causados pelos resíduos sólidos}

Quando os alunos foram solicitados a responder de qual local receberam o conhecimento sobre os problemas causados pelos resíduos sólidos, percebeu-se que a escola é o local onde os alunos mais obtêm conhecimento sobre o tema. A escola foi apontada por $70,1 \%$ dos alunos, seguida pelos programas de televisão $(14,2 \%)$, jornais $(3,8 \%)$, internet $(2,4 \%)$, revistas $(0,7 \%)$, entre outros $(7 \%)$, como pode ser observado na Figura 5. 


\section{ANAP

Figura 5: Fontes apontadas pelos alunos sobre a obtenção de conhecimento em relação aos problemas causados pelo gerenciamento inadequado dos resíduos sólidos, $(\mathbf{N}=\mathbf{2 8 8})$.

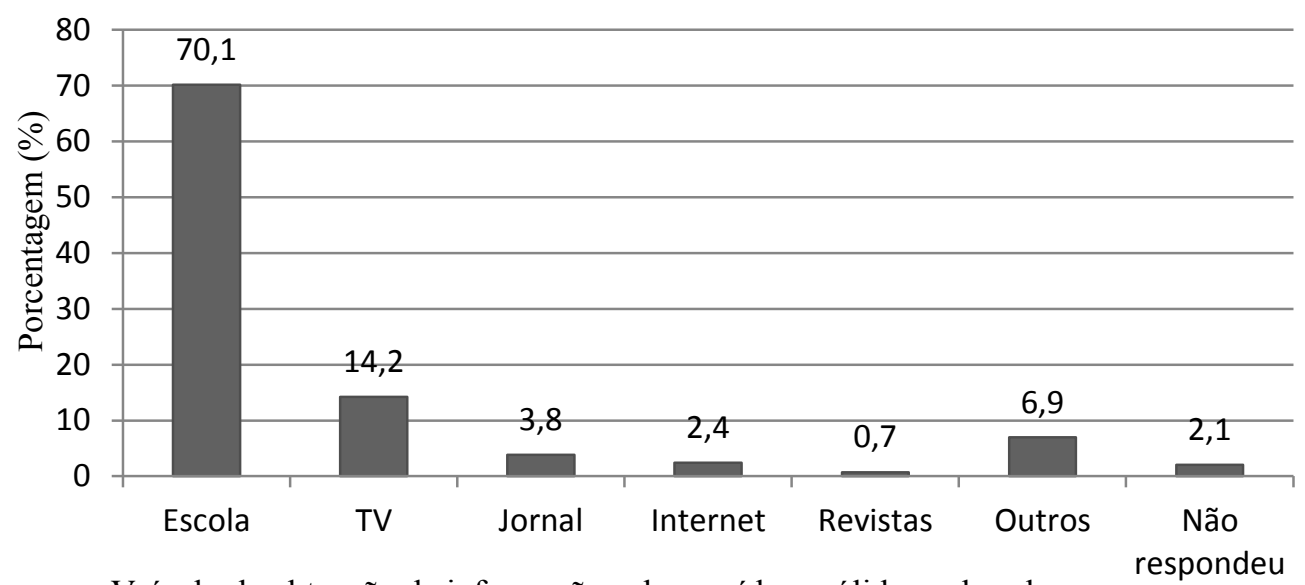

Veículo de obtenção de informação sobre resíduos sólidos pelos alunos

Fonte: Autoria própria (2013).

Essa questão proporcionou a identificação da importância da escola como meio de sensibilização para as questões ambientais. Assim, o ambiente escolar é percebido como o local onde os alunos são expostos com mais frequência a temas relacionados aos resíduos sólidos, sendo considerado o ambiente mais propício ao desenvolvimento de práticas de sensibilização ambiental.

De acordo com Esteves et al. (2011, p. 2), "a educação ambiental nas escolas públicas atingirá um grande público, já que a maioria dos estudantes do ensino básico brasileiro estuda nessas escolas, difundindo a consciência ambiental na população", entendendo que os indivíduos mais jovens são formadores, multiplicadores e transmissores de conhecimento.

\section{Concepção sobre a importância de realizar a separação dos resíduos sólidos}

Quando questionados sobre a importância da separação dos resíduos sólidos, 96,9\% ( $N=288$ ) dos alunos consideram importante realizar a separação dos resíduos sólidos que produzem em suas residências; $1,4 \%$ responderam que a separação não é importante; e 1,7\% não sabem ou não conhecem a importância de separar os resíduos sólidos.

Os dados apresentados revelam, segundo Helal e Felix (2011), que mesmo possuindo pouco conhecimento sobre o assunto, a maioria dos alunos compreende que é importante realizar a separação dos resíduos sólidos, o que possibilita uma melhora no processo de sensibilização. É função da educação ambiental proporcionar ao aluno conhecimento para que seja capaz de distinguir o verdadeiro valor do meio ambiente e aprender a fazer escolhas mais conscientes e responsáveis (CORRÊA; LUNARDI, 2007).

\section{Existência de coleta seletiva nas residências}

Procurando identificar a existência de coleta seletiva na residência dos alunos, perguntou-se: "existe coleta de "lixo" em sua casa?" Analisando as respostas dos alunos, verificou-se que em $83,3 \%(N=288)$ das casas existe coleta seletiva. Nas outras $16,7 \%$ das moradias não há a coleta seletiva. 


\section{ANAP

Os dados obtidos nesta questão concordam com os dados coletados pela Prefeitura Municipal de Mandirituba, os quais apontam que cerca de $70 \%$ das residências possuem coleta seletiva. Embora não muito eficiente, a prefeitura de Mandirituba oferece uma infraestrutura para a coleta dos resíduos sólidos gerados pelos habitantes, pois são de responsabilidade de cada município a coleta, o transporte, o tratamento, a destinação e disposição final ambientalmente adequadas dos resíduos sólidos (SHA'ATO et al., 2007).

\section{Responsabilidade pela coleta seletiva}

Complementando a questão anterior, os alunos foram solicitados a responder sobre quem realiza coleta em suas residências. Apenas os alunos que informaram haver coleta seletiva em suas residências foram convidados a responder esta questão. Com base nas respostas dos alunos, evidenciou-se que a prefeitura municipal de Mandirituba é a principal responsável pela coleta seletiva, representada por $78,8 \%$ das respostas. Estes também são dados bastante próximos aos informados pela prefeitura. Em seguida verificou-se que os catadores de materiais recicláveis são responsáveis por $8 \%$ da coleta seletiva nas residências dos entrevistados; e em 3,5\% das moradias a coleta é realizada pela prefeitura em conjunto com catadores. Os dados referentes à responsabilidade pela coleta seletiva estão representados na Figura 6.

Figura 6: Responsabilidade pela coleta dos resíduos sólidos nas residências, ( $N=240)$.

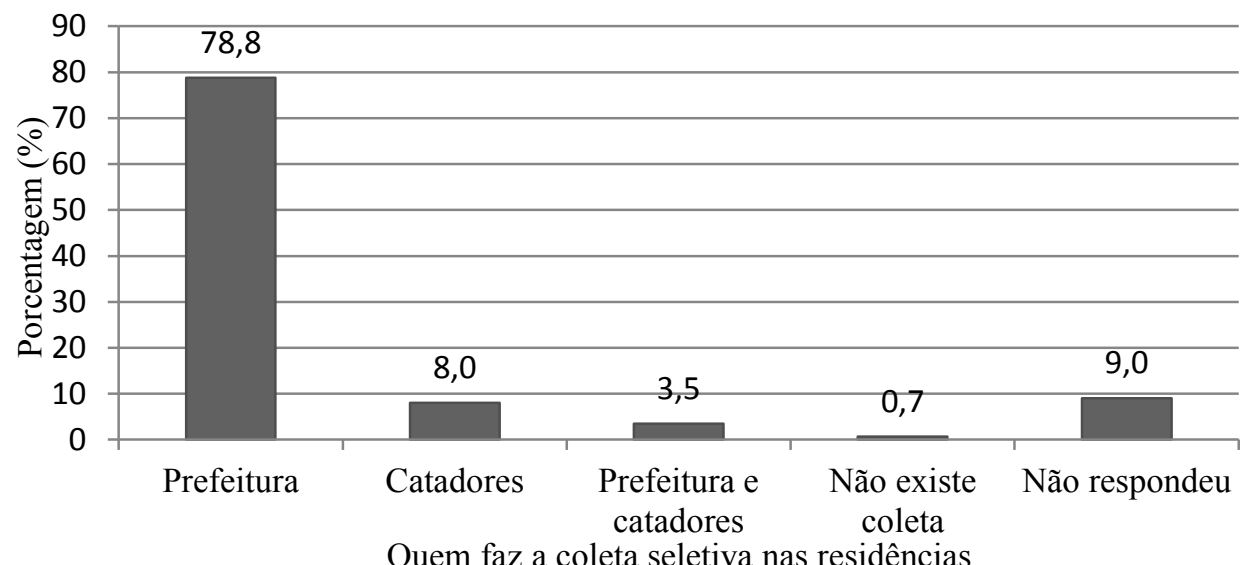

Fonte: Autoria própria (2013).

Analisando os dados obtidos com os alunos (Figura 6) e os da prefeitura municipal de Mandirituba, nota-se que, embora deficiente em alguns aspectos, como na coleta de resíduos perigosos, o município de Mandirituba oferece uma infraestrutura adequada, por meio da coleta seletiva dos resíduos sólidos e pela separação no centro de reciclagem. Atualmente, uma grande preocupação para os órgãos públicos locais é a criação de novas infraestruturas que atendam a gestão adequada dos resíduos sólidos (KUMAR; GOEL, 2009). Sendo assim, além de uma logística de coleta seletiva, é necessário conscientizar a população para que participe junto a esse sistema. 


\section{ANAP

Tipos de resíduos coletados (recicláveis e/ou orgânicos)

Buscando identificar o tipo dos resíduos que são coletados nas residências (recicláveis e/ou orgânicos), perguntou-se: que tipo de "lixo" é coletado? Nota-se que na maioria das residências (64,2\%), são coletados os dois tipos de resíduos sólidos (recicláveis e orgânicos); em $25,3 \%$ das casas são coletados somente os resíduos recicláveis; e em 4,5\% somente os resíduos orgânicos, como pode ser observado na Figura 7.

Figura 7: Tipos de resíduos sólidos que são coletados em cada residência, ( $\mathrm{N}=\mathbf{2 4 0}$ ).

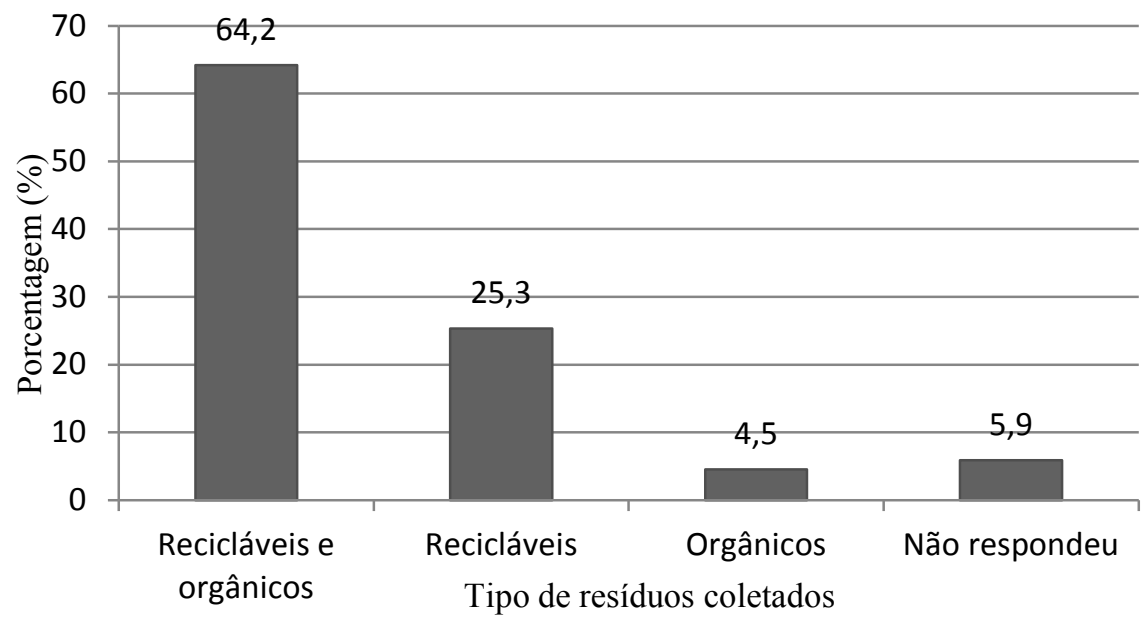

Fonte: Autoria própria (2013).

Nas áreas rurais, os resíduos orgânicos são coletados apenas em pontos estratégicos, conforme ilustrado na Figura 3, não sendo a coleta realizada no método "porta a porta". Muitos moradores das áreas rurais utilizam parte dos resíduos orgânicos para a alimentação de animais. Considerando essa hipótese, a quantidade de resíduos orgânicos gerados nessas regiões pode ser pequena, não sendo viável para a prefeitura realizar a coleta em cada residência. Logo se tem a necessidade de informar a parcela da população que reside em áreas rurais sobre as formas adequadas de separar os resíduos que podem ser reciclados (GHAFFARI; TALEBBEYDOKHTI, 2013), para que essa população também possa contribuir para o sistema de coleta seletiva (CORREA et al., 2012).

\section{Frequência de separação dos resíduos sólidos}

Buscando compreender a importância que os moradores atribuem à separação dos resíduos recicláveis e dos resíduos orgânicos, os alunos foram solicitados a responder com qual frequência suas famílias costumam realizar a separação de seus resíduos. Analisando as respostas dos alunos, percebe-se que os moradores não estão tratando a separação dos resíduos com a devida importância, pois $46,2 \%(\mathrm{~N}=240)$ dos alunos relataram que nem sempre realizam a separação; outros $12,5 \%$ nunca fazem a separação; e somente $41,3 \%$ responderam que sempre separam seus resíduos.

Pode-se observar que não há um compromisso por parte dos moradores em relação à separação dos resíduos sólidos. Ainda que $41,3 \%$ dos alunos relataram sempre realizar a 
separação dos resíduos sólidos, a grande maioria $(46,2 \%)$ afirmou que realizam a separação apenas às vezes, e $12,5 \%$ não fazem a separação. Conforme foi demonstrado em questão anterior, os alunos têm conhecimento da separação dos resíduos sólidos e dos graves problemas causados pela falta dessa separação, e também sabem que existe uma infraestrutura para realização da coleta seletiva. Entretanto, ainda é necessária a realização de um processo de sensibilização, para promover mudanças de atitude, proporcionando uma gestão de resíduos sólidos mais adequada do ponto de vista ambiental, social e econômico, pois o valor que as pessoas atribuem ao meio ambiente é resultado de processos de sensibilização à que são inseridas (SADIK; SADIK, 2014). Neste sentido, a educação ambiental é um processo capaz de modificar essas atitudes, sensibilizando os indivíduos para promover a separação dos resíduos sólidos (FERRAZ et al., 2013).

\section{Tipos de resíduos produzidos em maior quantidade}

Quando indagados sobre quais tipos de resíduos são produzidos em maior quantidade em suas residências, os alunos apontaram o plástico como sendo o tipo se resíduo sólido produzido em maior quantidade $(40,6 \%)(N=288)$; seguido pelo resto de alimentos $(20,1 \%)$; papel $(15,3 \%)$; metais e vidro ( $1 \%$ cada). Cerca de $22 \%$ dos alunos, no entanto, não souberam responder qual tipo de resíduo é produzido em maior quantidade em sua residência.

O plástico, material que constitui a maioria das embalagens dos produtos adquiridos pelas pessoas, é um dos tipos de resíduos mais produzidos pelas famílias dos alunos, fato demonstrado também em estudo realizado por Coelho (2012), que apontou o plástico como o resíduo mais produzido pelos moradores.

Segundo os dados revelados pelos alunos em suas percepções, os resíduos recicláveis constituem a maior fração dos resíduos sólidos produzidos em Areia Branca dos Assis e entorno. Este fato pode ser atribuído aos costumes da população, principalmente a população residente em ambientes rurais (44\%) que possui o hábito de oferecer, diariamente, os restos de resíduos orgânicos aos animais que criam em suas propriedades, isso faz com que os resíduos orgânicos permaneçam pouco tempo em suas residências, não se acumulando e não sendo percebidos pelos alunos. Várias famílias dos alunos que frequentam o colégio em Areia Branca dos Assis residem em comunidades rurais próximas.

Por outro lado, segundo a Secretaria Municipal de Meio Ambiente de Mandirituba, os resíduos recicláveis como o plástico e papel, são coletados apenas uma vez por semana. E no período entre uma coleta e outra, os resíduos se acumulam e tornam-se mais perceptíveis aos olhos dos alunos.

Sendo assim, torna-se mais importante a realização de projetos que visem a separação dos resíduos recicláveis, promovendo a valorização econômica e a reciclagem desses materiais.

\section{Percepção sobre a diferença entre resíduos recicláveis e orgânicos}

Procurando identificar a percepção dos alunos sobre a diferença entre resíduos recicláveis e orgânicos, perguntou-se: "você sabe a diferença entre "lixo" reciclável e "lixo" orgânico?". Com a análise das respostas dos alunos, identificou-se que $69 \%(\mathrm{~N}=288)$ relataram conhecer a diferença entre resíduos recicláveis e resíduos orgânicos; os outros 31\% responderam não conhecer essa diferença. Porém, essa questão permitia ao aluno expressar sua opinião. Os alunos que responderam saber a diferença entre resíduos recicláveis e orgânicos foram solicitados a escrever um pequeno parágrafo explicando sua resposta. Assim, foi possível 
identificar os alunos que realmente possuem esse conhecimento. Verificou-se que do total de alunos, apenas $46,6 \%$ realmente sabem a diferença entre resíduos recicláveis e resíduos orgânicos. Muitos dos alunos que afirmaram saber a diferença entre os tipos de resíduos, relataram que os resíduos orgânicos não podem ser reaproveitados (Quadro 2), sendo que podem ser reutilizados para fazer a compostagem.

Quadro 2: Respostas dos alunos quando questionados sobre a diferença entre resíduos recicláveis e orgânicos.

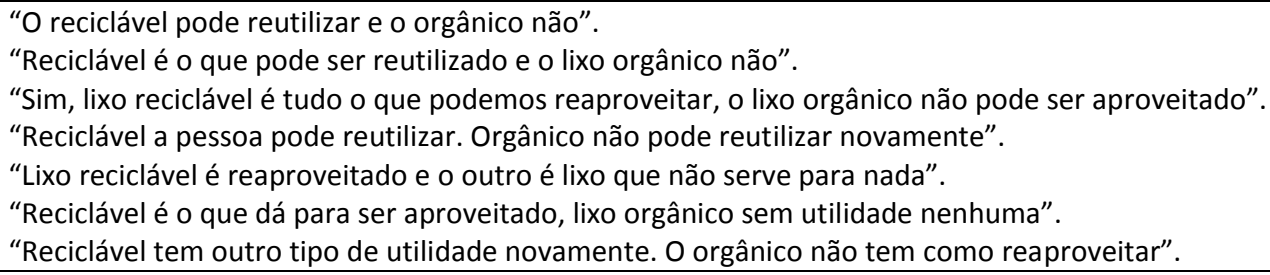

Fonte: Autoria própria (2013).

Para que a separação dos resíduos seja eficiente, é necessário que a população saiba quais resíduos podem ser reciclados, para que não sejam misturados aos resíduos orgânicos, perdendo assim o seu valor (CORREA et al., 2012). Neste contexto, torna-se de extrema importância a realização de projetos de educação ambiental, possibilitando que as pessoas obtenham um conhecimento mais amplo referente aos resíduos sólidos (TOZONI-REIS, 2008).

\section{Percepção dos alunos sobre os locais de disposição final dos resíduos sólidos}

Quando indagados se sabiam sobre a disposição final dos resíduos sólidos, os alunos puderam expor suas próprias opiniões, pois se tratava de uma questão aberta. Analisando as respostas, os lixões foram apontados por $45,1 \%(\mathrm{~N}=288$ ) dos alunos como sendo o destino final dos resíduos produzidos em suas residências; $22,9 \%$ responderam que seus resíduos vão para aterros sanitários; também foram citados centros de reciclagem $(6,6 \%)$ e caminhão de coleta $(3,1 \%)$; as respostas de $1,4 \%$ dos alunos foi a queima; e $0,3 \%$ informaram que enterram seus resíduos. Notou-se também que $20,5 \%$ não sabem qual é o destino dos resíduos sólidos depois que saem de suas casas.

Segundo entrevista realizada na Secretaria Municipal de Meio Ambiente, os resíduos sólidos recicláveis produzidos em Mandirituba são destinados a um centro de separação localizado no próprio município e posteriormente são vendidos no município de Curitiba para empresas especializadas em reciclagem. Os resíduos orgânicos são dispostos em aterro sanitário localizado no município vizinho de Fazenda Rio Grande.

Os alunos que responderam que queimam ou enterram os resíduos também relataram que residem em locais que não são atendidos pela coleta seletiva.

Nota-se que grande parte dos alunos não sabe o destino final dos resíduos produzidos em suas residências. Também se observou que algumas famílias queimam ou enterram seus resíduos, consideradas atitudes inadequadas para disposição dos mesmos. É necessário sensibilizar essas pessoas com a finalidade de fazê-las mudar suas atitudes (WANG et al., 2013), proporcionando mais conhecimento sobre as formas adequadas de destinação dos resíduos sólidos (GHAFFARI; TALEBBEYDOKHTI, 2013). 


\section{CONCLUSÕES}

Baseado no estudo das percepções ambientais de alunos de colégio público de Areia Branca dos Assis, percebe-se que os estudantes investigados apresentaram, de uma forma geral, uma percepção ambiental incipiente. Notou-se que parte dos alunos não soube responder algumas perguntas, o que pode estar relacionado com a falta de conhecimento dos alunos, as falhas no processo ensino-aprendizagem, ou até mesmo à dificuldade de transcrever suas ideias para o papel.

Foi observado que os alunos, mesmo possuindo pouco conhecimento sobre o assunto, compreendem que é importante realizar a separação dos resíduos sólidos e também conhecem as consequências que o gerenciamento inadequado dos resíduos sólidos causa ao meio ambiente. Porém, ainda que possuindo tais conhecimentos, não há conscientização de toda a população para realizar a separação dos resíduos sólidos. Essa constatação revela a necessidade da inserção de projetos de sensibilização ambiental focados na gestão e gerenciamento adequados dos resíduos sólidos.

Também se percebeu que a escola foi apontada pela maioria dos alunos como o local que thes oferecia conhecimentos referentes à temática resíduos sólidos. Assim, a escola apresenta-se como o local onde os alunos são expostos com mais frequência a temas relacionados aos resíduos sólidos, sendo considerada, portanto como o ambiente mais propício ao desenvolvimento de estratégias de educação ambiental.

\section{REFERÊNCIAS BIBLIOGRÁFICAS}

AMARO, A.; PÓVOA, A.; MACEDO, L. A arte de fazer questionários. Relatório de pesquisa. Porto: Faculdade de Ciências, Departamento de Química da Universidade do Porto. 2004/2005.

AZEVEDO, G. O. D. POR MENOS LIXO: A minimização dos resíduos sólidos urbanos na cidade do Salvador/Bahia. 2004. 148 f. Dissertação (Mestrado em Engenharia Ambiental Urbana) - Universidade Federal da Bahia, Salvador, 2004.

BLANCHET-COHEN, N.; REILLY, R. C. Teachers' perspectives on environmental education in multicultural contexts: Towards culturally-responsive environmental education. Teachingand Teacher Education. 36. 12-22. 2013.

BRASIL. Política Nacional de Resíduos Sólidos. 2010. Disponível em: http://www.camara.gov.br/sileg/integras/501911.pdf. Acesso em: 11/04/2012.

CAMPOS, M. C. C.; NETO, N. M. S. M.; VERAS, E. S.; SOUZA, Z. G. E. F. Percepção ambiental: experiência em escolas de ensino fundamental em Humaitá (AM). Ambiência Guarapuava (PR), v.8 n.1 p.35-46, ISSN 1808 - 0251. 2012.

CASSERES, E. M. M. D. Projeto de educação ambiental na Escola Municipal São Sebastião comunidade de Aracampina, Ilha de Ituqui, Santarém, Pará. Rev. Comunicação e Educação Ambiental. Volume 1 - No 1Janeiro/Junho de 2011.

CHAGAS, A. T. R. O questionário na pesquisa científica. Rev. Administração On-Line, v. 1, n. 1, jan.fev. mar. 2000. Disponível

em: http://www4.fct.unesp.br/docentes/geo/necio_turra/pesquisa\%20em\%20geografia/metodologia\%20de\%20questio n\%e1rio.pdf. Acesso em: 23/05/2012

COELHO, A. A. Percepção ambiental dos moradores ribeirinhos do médio Itapecuru em Rosário-MA como subsídio a uma proposta de educação ambiental. Rev. Brasileira de Educação Ambiental, Rio Grande, V. 7, No 2: 29-36, 2012. 
COELHO, H. M. G.; LANGE, L. C.; JESUS, L. F. L.; SARTORI, M. R. Proposta de um índice de destinação de resíduos sólidos industriais. Eng Sanit Ambient. v.16 n.3. jul/set 2011.

CORREA, B. F.; MACEDO, G. G.; SANTOS, A. E. C.; RUTHES, T. C. C. Educação Ambiental, coleta seletiva de resíduos sólidos: gincana realizada pelo Projeto Rondon em Apicum - Açu - MA. $4^{\circ}$ Congresso Internacional de Educação, Pesquisa e Gestão. 2012.

CORRÊA, L. B.; LUNARDI, V. L. A educação ambiental no processo de formação em saúde: os resíduos sólidos de serviço de saúde numa perspectiva teórica. Rev. eletrônica Mestr. Educ. Ambient. ISSN 1517-1256, v 18, Janeiro a Julho de 2007.

ESTEVES, R. C.; SILVA, A. B. C. G.; ROZA, F. C.; GONÇALVES, L. P.; FREITAS, L. S.; PAULA, T. P. Como aplicar educação ambiental no dia a dia de uma escola pública. Rev. Comunicação e Educação Ambiental. Volume 1 - No 1Janeiro/Junho de 2011.

FERRAZ, C. B. O.; BARBOSA, S. A; CAJUELA, K. B.; BURATO, G.; PEREIRA, N.; COSTA, D. M.; FERNADES, E. C.; DAUER, P. G.; SAKAMOTO, J. A.; SHIOTA, R. T.; GOULART, A. L.; SILVA, A. V. J.; ROSSIN, B. G. Elaboração de proposta de educação ambiental para a rede de escolas municipais de Presidente Prudente. Disponível em: http://www.unesp.br/prograd/ENNEP/Trabalhos\%20em\%20pdf\%20-\%20Encontro\%20de\%20Ensino/T8.pdf . Acesso em: 03/09/2013.

GHAFFARI, S.; TALEBBEYDOKHTI, N. Status of Environmental Engineering Education in Various Countries in Comparison With the Situation in Iran. Procedia - Social and Behavioral Sciences. 102. 591 - 600. 2013.

HELAL, M. P.; FELIX, C. C. A. Implantação de coleta seletiva em um condomínio de casas na Barra da Tijuca. Rev. Comunicação e Educação Ambiental. Volume 1 - No 1- Janeiro/Junho de 2011.

IBGE. Instituto Brasileiro de Geografia e Estatística, Censo Demográfico 2010. Disponível em: http://www.ibge.gov.br/home/estatistica/populacao/censo2010/primeiros_resultados/default_primeiros_resultad os.shtm. Acesso em: 10/04/2012.

IPARDES. Instituto Paranaense de Desenvolvimento Econômico e Social, Perfil dos Municípios. Disponível em: http://www.ipardes.gov.br/perfil_municipal/MontaPerfil.php?Municipio=83800\&btOk=ok. Acesso em: 04/07/2012.

KUMAR, K. N.; GOEL, S. Characterization of Municipal Solid Waste (MSW) and a proposed management plan for Kharagpur, West Bengal, India. Resources, Conservation and Recycling.v.53. 166-174. 2009.

MACEDO, R. L. G.; FREITAS, M. R.; FERREIRA, E. B.; FREITAS, M. P. Em busca da conservação ambiental: a contribuição da percepção ambiental para a formação e atuação dos profissionais da química. Química Nova, Vol. 33, No. 4, 988-993, 2010.

MARCOMIN, F. E.; PEREIRA, C.C.; SILVA, F. K.; RICKEN, I. Percepção e sensibilização ambiental como instrumentos à educação ambiental. Rev. Eletrônica Mestr. Educ. Ambient. E-ISSN 1517-1256, v. 30, n.2, p. 86 - 106, jul./dez. 2013.

MARQUES, M. A.; FILHO, H. O.; MAGALHÃES, C. A. O. Percepção de agricultores acerca da importância dos morcegos na manutenção da mata ciliar. Rev. eletrônica Mestr. Educ. Ambient. ISSN 1517-1256, v. 26, janeiro a junho de 2011.

MAYER, F. S.; FRANTZ, C. M. The importance of connection to nature in assessing environmental education programs. Studies in Educational Evaluation. 2013.

MENEZES, J. P. C.; BERTOSSI, A. P. A. Percepção ambiental dos produtores agrícolas e qualidade da água em propriedades rurais. Rev. eletrônica Mestr. Educ. Ambient. ISSN 1517-1256, v. 27, julho a dezembro de 2011. 
MONTEIRO, V. G. ROCHA, S. P. M.; SILVA, G. S. Avaliação da percepção ambiental da Comunidade Ribeirinha Vila Rio no município de Conceição do Araguaia - PA. III Congresso Brasileiro de Gestão Ambiental, Goiânia/GO, 2012.

MOYSÉS, G. L. R.; MOORI, R. G. Coleta de dados para a pesquisa acadêmica: um estudo sobre a elaboração, a validação e a aplicação eletrônica de questionário. XXVII Encontro Nacional de Engenharia de Produção. Foz do Iguaçu, PR, Brasil, 09 a 11 de outubro de 2007.

MUCELIN, C. A.; BELLINI, M. Lixo e impactos ambientais perceptíveis no ecossistema urbano. Sociedade \& Natureza, v.20 (1): 111-124, Uberlândia. Jun. 2008.

PREFEITURA MUNICIPAL DE SÃO JOSÉ DOS PINHAIS. Mapa de localização do município. Acesso em: 13/08/2014. Disponível em: http://www.sjp.pr.gov.br/localizacao/.

SADIK, F. SADIK, S. A study on environmental knowledge and attitudes of teacher. Procedia - Social and Behavioral Sciences.116.2379-2385. 2014.

SANTOS, P. J. A.; SILVA, M. M. P.; COUTO, M. G.; BORGES, V. G. Relação entre a percepção ambiental de docentes e discentes do ensino fundamental II de uma escola pública do semiárido paraibano com as características do bioma caatinga. Rev. Eletrônica Mestr. Educ. Ambient. ISSN 1517-1256, V. 30, n. 1, p. 38 - 53, jan./ jun. 2013.

SHA'ATO, R.; ABOHO, S.Y.; OKETUNDE, F.O.; ENEJI, I.S.; UNAZI, G.; AGWA S. Survey of solid waste generation and composition in a rapidly growing urban area in Central Nigeria. Waste Management. V 27. 352-358. 2007.

SILVA, A. D. V.; MENDONÇA, A. W.; MARCOMIN, F. E,; MAZZUCO, K. T. M.; BECKER, R. R. Percepção ambiental como ferramenta para processos de educação ambiental na universidade. Rev. eletrônica Mestr. Educ. Ambient. ISSN 1517-1256, v. 27, julho a dezembro de 2011.

SILVEIRA, G. T. R.; AFONSO, C. G.; ARRUDA, L. N. Resíduos sólidos e educação ambiental para a comunidade do Instituto de Ciências Biológicas e da Saúde da PUC Minas: uma oportunidade de reflexão sobre o discurso teórico e a prática ambiental no mundo acadêmico. Rev. eletrônica Mestr. Educ. Ambient. ISSN 1517-1256, v. 21, julho a dezembro de 2008.

SOUZA, G. S.; MACHADO, P. B.; REIS, V. R.; SANTOS, A. S.; DIAS, V. B. Educação como ferramenta para o manejo de resíduos sólidos no cotidiano escolar. Revbea, Rio Grande, V. 8, No 2:118-130, 2013.

SPAZZIANI, M. L.; SILVA, P. G. F. Planejamento e Avaliação em Projetos de Educação Ambiental. Curitiba: IESDE, 2009.

TOZONI-REIS, M. F. C. Metodologias Aplicadas à Educação Ambiental. 2. ed. Curitiba: IESDE, 2008.

VILLAR, L. M. ALMEIDA, A. J.; LIMA, M. C. A.; ALMEIDA, J. L. V.; SOUZA, L. F. B.; PAULA, V. S. A percepção ambiental entre os habitantes da região nordeste do Estado do Rio de Janeiro. Rev Enferm set; 12 (3): 537-43, 2008.

WANG, Y.; SHI, H.; SUN, M.; HUISINGH, D.; HANSSON, L.; WANG, R. Moving towards an ecologically sound society? Starting from Green universities and environmental higher education. Journal of Cleaner Production. 61, 1-5. 2013. 